\title{
Punishment of schedule-induced wheel running
}

\author{
GLEN D. KING and JOSEPH P. SIDES \\ Auburn University, Auburn, Alabama 36830
}

\begin{abstract}
Four naive female food-deprived rats were given free access to running in a wheel. During the baseline phase 100 food pellets were placed in the magazine at the beginning of each 100-min session. Subsequent experimental phases consisted of presenting the food pellets on a FT 60-sec schedule with 2-mA .5-sec electric shock contingent on postpellet running. Electric shock reduced the absolute number of wheel turns but resulted in faster running. With discontinuance of shock, running dramatically increased to preshock levels within 3 days.
\end{abstract}

In the past 12 years an increasing amount of attention has been directed toward unprogrammed behaviors that occur as adjuncts (Falk, 1972) to a schedule of reinforcement or punishment. Schedule-induced polydipsia, first documented by Falk (1961), may be considered a prototype of all such adjuncts. These phenomena are labeled schedule-induced because an intermittent schedule of reinforcement is a necessary condition for their occurrence.

Levitsky and Collier (1968) and Segal (1969) reported that when rats were deprived of food and exposed to an intermittent food-delivery schedule, excessive "schedule-induced" wheel running developed. In the Segal study, water and running were freely available, and immediately following food delivery, the rats drank and then ran. Schedule-induced wheel running has also occurred as an adjunct to the intermittent presentation of water to water-deprived rats (King, 1974).

Although a great number of investigations have been conducted on the parameters that are necessary and/or sufficient for the occurrence of schedule-induced behaviors, relatively little experimentation has been conducted on the conditions under which schedule-induced behaviors are eradicated. Roll, Schaeffer, and Smith (1969) found that, after exposing polydipsic rats to gamma irradiation (100R), one subject showed only a slight decrease in fluid consumption while the other subject showed a slight increase. Increasing the dosage to $200 \mathrm{R}$ resulted in only a slight drop in consumption for both subjects, and the preirradiation intake levels were recovered within six sessions. Punishment of schedule-induced bheaviors by mild electric shock has reportedly resulted in some increases in those behaviors (King, 1972; Galantowicz \& King, 1975).

This research was supported in part by Public Health Service Research Grants MH-08775 and MH-12025 and by the Auburn University kesearcn Councu. Kobert $W$. Schaetter sponsors this paper and takes full editorial responsibility for its contents.
The purpose of this experiment was to investigate the effects of punishment on a schedule-induced behavior (wheel running). Specifically, the authors were interested in whether the contingent application of electric shock for wheel running would (1) increase or decrease that behavior and (2) have lasting effects once the shock was discontinued.

\section{METHOD}

\section{Subjects}

The subjects were four naive female albino rats between 250-290 g ad-lib weight. The animals were individually housed under relatively constant environmental conditions. During the experiment, the subjects were maintained at $80 \%$ of their free-feeding weights with water continuously available in the home cage.

\section{Apparatus}

One $35-\mathrm{cm}$ diam running/shock wheel previously described by Schaeffer (1966) was employed. Delivery of 2-mA, .5-sec unscrambled electric shock to the grid floor was accomplished by a Grayson-Stadler shock generator, Model E 6070B. Pellet delivery (45-mg Noyes food pellets) was controlled by a Lehigh Valley Electronics pellet dispenser. An Esterline Angus graphic voltmeter, Model AW was used to record pellet delivery, shock onset, and the number, direction, duration, and intensity of wheel turns. All equipment was programmed by standard relay circuitry.

\section{Procedure}

The experiment consisted of daily 100-min sessions separated into five phases. Wheel running behavior was the dependent variable in each phase. During Phase 1 , the food-deprived rats were placed individually in the wheel and 100 pellets were placed in the foodcup. Wheel running was freely available in this and all other phases of the experiment. Phase 2 consisted of presentation of the 100 pellets on a FT 60 -sec schedule. An FT schedule delivers a food pellet on a periodic schedule independently of the organism's response. In Phase 3 the FT 60 -sec schedule was maintained with the addition of a $2-\mathrm{mA}$, .5 -sec shock contingent on one wheel revolution. Subjects received no more than one shock per interpellet interval and could avoid shock completely by not running. Phases 4 and 5 were replications of Phases 2 and 1, respectively. Wheel running stability for each subject was achieved before each phase change. Stability for each subject was defined as the condition in which the mean wheel revolutions for the last three sessions minus the 
Table 1

Mean Number of Run Bursts (RB) of 5-Sec Duration or Greater and Mean Rate of Running in Revolutions Per Second (RS) Across the Last 3 Days in Each Experimental Phase for Each Subject

\begin{tabular}{|c|c|c|c|c|c|c|c|c|c|c|}
\hline \multirow[b]{2}{*}{ Subjects } & \multicolumn{2}{|c|}{ Phase 1} & \multicolumn{2}{|c|}{ Phase 2} & \multicolumn{2}{|c|}{ Phase 3} & \multicolumn{2}{|c|}{ Phase 4} & \multicolumn{2}{|c|}{ Phase 5} \\
\hline & $\mathrm{RB}$ & $\mathrm{RS}$ & $\mathrm{RB}$ & $\mathrm{RS}$ & $\mathrm{RB}$ & $\mathrm{RS}$ & $\mathrm{RB}$ & $\overline{\mathrm{RS}}$ & $\mathrm{RB}$ & $\mathrm{RS}$ \\
\hline $\begin{array}{l}17 \\
18 \\
19 \\
20\end{array}$ & $\begin{array}{r}23.0 \\
67.3 \\
130.3 \\
70.0\end{array}$ & $\begin{array}{l}.7 \\
.8 \\
.8 \\
.8\end{array}$ & $\begin{array}{r}60.0 \\
181.0 \\
127.7 \\
97.0\end{array}$ & $\begin{array}{l}.6 \\
.8 \\
.8 \\
.8\end{array}$ & $\begin{array}{r}.0 \\
4.0 \\
26.6 \\
7.3\end{array}$ & $\begin{array}{r}* \\
.9 \\
1.5 \\
1.1\end{array}$ & $\begin{array}{r}30.3 \\
147.7 \\
130.3 \\
75.3\end{array}$ & $\begin{array}{l}.5 \\
.7 \\
.9 \\
.7\end{array}$ & $\begin{array}{r}47.0 \\
156.0 \\
145.0 \\
122.0\end{array}$ & $\begin{array}{l}.6 \\
.7 \\
.8 \\
.6\end{array}$ \\
\hline Mean & 72.7 & .8 & 116.4 & .8 & 9.5 & 1.2 & 95.9 & .7 & 117.3 & .7 \\
\hline
\end{tabular}

*.Vo running occurred

mean for the preceding three sessions, divided by the mean of the last six sessions did not exceed .20 .

\section{RESULTS AND DISCUSSION}

The mean number of run bursts of $5 \mathrm{sec}$ or greater duration and the mean number of revolutions per second across the last 3 days in each phase for each subject is presented in Table 1. The number of run bursts increased for three of four subjects from the baseline to the schedule-induced running phase (Phase 2). When the run-contingent shock was applied in Phase 3 all subjects exhibited a decrease in the number of run bursts initiated. When shock was discontinued in Phases 4 and 5 , running burst initiations dramatically increased to preshock levels. When the second baseline (Phase 5) was instituted, previous lower levels of running in Phase 1 were not recovered, i.e., all subjects initiated more run bursts in Phase 5 than in Phase 1.

Perhaps the most interesting data are the rates at which the subjects ran during each condition. For all phases except Phase 3, the subjects ran at a fairly constant rate of about .7 to .8 revolutions per second. Although the frequency with which run burts were initiated during Phase 3 were lowest for all subjects, when running was initiated, the subjects ran at a higher rate (more revolutions per second) than in any other phase. Observation of the subjects' behavior in the wheel during this phase revealed that the subjects ate the pellet and then vascillated between remaining still and starting to run. When the run response was initiated, the subjects lunged at the side of the wheel, initially running at a rate faster than in previous and subsequent phases. The delivery of shock had no effect on the speed of running and running usually continued to the end of the interpellet interval. When the run-contingent shock was discontinued, the subjects showed an immediate and dramatic recovery of preshock schedule-induced wheel running levels within 3 days.
Although the imposition of run-contingent shock drastically reduced the absolute number of run bursts for all subjects, three of the four subjects exhibited an increase in another dimension of the run response-rate of running. This implies that for some behaviors (perhaps especially the class of schedule-induced or adjunctive behaviors) the direct contingent application of a punishing stimulus for a response may have differential effects on the various components of the response. All too often the effects of punishment are monitored in only one response dimension while other response dimensions go unnoticed. These results suggest that those unmonitored response dimensions may be exhibiting important changes as a result of the application of a punishing stimulus. Finally, schedule-induced wheel-running showed remarkable recovery once the electric shock was discontinued, illustrating the strong motivational properties of schedule-induced behaviors.

\section{REFERENCES}

Falk, J. L. Production of polydipsia in normal rats by an intermittent food schedule. Science, 1961, 133, 195-196.

Falk, J. L. The nature and determinants of adjunctive behavior. In R. M. Gilbert and J. D. Keehn (Eds.), Schedule effects: Drugs, drinking, and aggression. Toronto: University of Toronto Press, 1972.

Galantowicz, E. P. \& King, G. D. The effect of three levels of lick-contingent footshock on schedule-induced polydipsia. Bulletin of the Psychonomic Society, 1975, 5, 113-116.

King, G. D. Three experiments on stress-induced behaviors Unpublished doctoral dissertation. Florida State University. 1972.

King, G. D. Wheel running in the rat induced by a fixed-time presentation of water. Animal Learning \& Behavior, 1974, $2,325-328$.

Levitsky, D. A., \& Collier, G. Schedule-induced wheel running. Physiology and Behavior, 1968, 3, 571-573.

Roll, D., Schaeffer, R. W., \& Smith, J. C. Effects of a conditioned taste aversion on schedule-induced polydipsia. Psychonomic Science, 1969, 16, 39-40.

Schaeffer, R. W. A new device for programming contingencies between drinking, running, and lever-pressing. Journal of the Experimental Analysis of Behavior, 1966, 9, 529-533.

Segal, E. F. The interaction of psychogenic polydipsia with wheel running in rats. Psychonomic Science, 1969, 14, 141-142, 144 .

(Received for publication December 15, 1974.) 